\title{
DIGITAL TECHNOLOGY IN COMPLETE DENTURE PROSTHODONTICS: A REVIEW OF LITERATURE
}

\author{
Mohamed H. Abdelnabi* and Amal A. Swelem**
}

\begin{abstract}
Background: Computer-aided design and computer-aided manufacturing (CAD/CAM) technology has expanded to embrace implant, maxillofacial and removable prosthodontics including the fabrication of complete dentures. However, despite that the implementation of computer-aided technology with edentulous patients seemed to improve and simplify complete denture treatment as it significantly reduced the number of patient visits, yet still a limited number of reports described its use for complete denture fabrication
\end{abstract}

Objective: This literature review will cast light on digital technology and its implementation in complete denture prosthodontics including its advantages, limitations, techniques and will present the articles that reported or investigated this topic and their outcomes including clinical or patientbased outcomes

Materials and methods: An independent electronic search of the English language literature was conducted by 2 investigators (authors), in bibliographic database MEDLINE, EMBASE, the Cochrane Library and Google up to March 2017 using certain key words. The electronic search was conducted in 3 stages in a systematic order. Stage 1, involved acquiring a record of titles from the electronic databases, which was then independently analysed by each investigator to extract relevant titles based on the predetermined inclusion criteria. The investigators independently applied the exclusion criteria, and any inconsistency was resolved by discussion. In uncertainty situations, the disputed article was included in the second (abstract) stage for contemplation. Stage 2 involved screening the abstracts of all selected titles by both investigators separately. Once more, any disagreement between the investigators was discussed, and, in uncertain situations, the abstract was included in the third and last stage of full-text analysis. At stage 3, all full text articles that were included were studied by the two investigators. This was followed by applying the final exclusion criteria and reviewing the final list of articles thoroughly and in depth to extract all relevant qualitative and quantitative data.

* Associate Professor, Oral and Maxillofacial Prosthodontic Department, Faculty of Dentistry, King Abdulaziz University, Jeddah, Saudi Arabia; Removable Prosthodontic Department, Faculty of Dentistry, Minia University, Egypt.

** Associate Professor, Oral and Maxillofacial Prosthodontic Department, Faculty of Dentistry, King Abdulaziz University, Jeddah, Saudi Arabia; Removable Prosthodontic Department, Faculty of Oral and Dental Medicine, Cairo University, Egypt. 
Results: The review included a total of 20 articles. 2 studies described techniques for digital arrangement of denture teeth, 13 studies described techniques for digital fabrication of digital complete dentures either using rapid prototyping technology or computerized numerical control milling. The other 5 articles were clinical studies that assessed the clinical and patient-based outcomes of digitally-fabricated dentures.

Conclusions: Digitally fabricated dentures can be an effective and time-efficient option for completely edentulous patients with favourable clinical and patient-centered outcomes. They are preferred by clinicians and patients as they significantly reduced clinical time and number of appointments, improved retention as well as digital archivability and hence reproducibility. However, dental literature lacks short-term and long term prospective clinical studies in this field to be able to reach definitive conclusions.

\section{INTRODUCTION}

Despite the exceedingly growing use of dental implants, complete dentures still represent an indispensable treatment option for some edentulous individuals who cannot afford or are contraindicated for implant therapy. Over the past 100 years, complete denture fabrication has not changed considerably and was mainly based on conventional techniques which consists of multiple steps requiring traditionally 4 to 5 clinical appointments, from the preliminary impressions to denture placement, and lengthy laboratory procedures. ${ }^{1,2}$ This usually requires substantial human intervention and extensive material manipulation, which may lead to inaccuracies, processing errors, and increased time and expenses. ${ }^{1}$

For several years now, computer-aided design and computer-aided manufacturing (CAD/CAM) technology has been available, and continues to develop in the field of fixed prosthodontics ${ }^{3-5}$ showing significant impact on the design and fabrication of fixed dental prostheses.$^{6-9}$ Recently however, it has expanded to embrace implant, maxillofacial and removable prosthodontics 10-12 including the fabrication of complete dentures., , $13-32^{-12}$

Despite that the implementation of computeraided technology with edentulous patients seemed to improve and simplify complete denture treatment as it significantly reduced the number of patient visits $^{2}$, yet still a limited number of reports described its use for complete denture fabrication. ${ }^{13-18,20,21}$ This is possibly due to the characteristic nature of fabricating complete dentures, which involves multiple steps of recording, transferring, evaluating, then creating artificial substitutes for teeth and gingiva that should harmonize with the patient's face and mouth. ${ }^{32}$ All these elements call for the clinician's artistic and technical judgment, which is more difficultly adapted to CAD/CAM technology than tooth-supported or intra-coronal restorations. Hence, prospective clinical trials are still lacking in this rapidly evolving field ${ }^{2}$ and scientific validation of this technology requires further research. ${ }^{22}$

This literature review will cast light on digital technology and its implementation in complete denture prosthodontics including its advantages, limitations, techniques and will present the articles that reported or investigated this topic and their outcomes including clinical or patient-based outcomes.

\section{METHODOLOGY}

An independent electronic search of the English language literature was conducted by 2 investigators (authors), in bibliographic database MEDLINE, EMBASE, the Cochrane Library and Google up to March 2017. Key words used for the search were "CAD-CAM dentures", "digital technology in complete dentures", "computer-aided manufacturing in removable dentures", "computeraided design in removable dentures", "digitally- 
fabricated dentures", "digital dentures", "digital removable dental prostheses". Searches were not restricted by publication date and were not restricted to clinical studies only.

The inclusion criteria were as follows: 1) any English language article in a peer-reviewed scientific journal; 2) any article involving computeraided design and computer-aided manufacturing of complete dentures or denture bases 3) any full text article considering or describing digital technology with removable complete dentures. The exclusion criteria were as follows: 1) articles that described CAD-CAM technology in other than complete denture prosthodontics, 2) manuals or explanations of techniques, 3) Review articles.

The electronic search was conducted in 3 stages in a systematic order. Stage 1, involved acquiring a record of titles from the electronic databases, which was then independently analyzed by each investigator to extract relevant titles based on the predetermined inclusion criteria. The investigators independently applied the exclusion criteria, and any inconsistency was resolved by discussion. In uncertainty situations, the disputed article was included in the second (abstract) stage for contemplation. Stage 2 involved screening the abstracts of all selected titles by both investigators separately. Once more, any disagreement between the investigators was discussed, and, in uncertain situations, the abstract was included in the third and last stage of full-text analysis. At stage 3, all full text articles that were included were studied by the two investigators. This was followed by applying the final exclusion criteria and reviewing the final list of articles thoroughly and in depth to extract all relevant qualitative and quantitative data.

\section{RESULTS}

The following articles were reviewed based on the search strategy explained in the methods: 15 articles that described different techniques for digital arrangement of denture teeth and fabrication of digital complete dentures: \{Maeda et al (1994) ${ }^{13}$, Kawahata et al (1997) $)^{14}$, Busch and Kordass (2006) ${ }^{15}$, Sun et al (2009) $)^{16}$, Kanazawa et al (2011) $)^{17}$, Zhang et al $(2011)^{18}$, Goodacre et al $(2012)^{20}$, Inokoshi et al (2012) ${ }^{21}$, Infante et al (2014) $)^{24}$, McLaughlin and Van Ramos (2015) ${ }^{33}$ Belgin et al 2016 ${ }^{34}$, Neumeier and Neumeier 2016 ${ }^{35}$, Wimmer et al $(2016)^{29}$, Yilmaz et al (2016) ${ }^{36}$, Schweiger et al $\left.(2017)^{31}\right\}$ and 5 clinical studies that assessed the clinical outcomes of digitally-fabricated dentures \{Kattadiyil et al $(2015)^{25}$, Saponaro et al $(2016)^{26}$, Bidra et al $(2016)^{32}$, Schwindling and Stober $(2016)^{37}$, Al Helal et al $(2017)^{38}$ \}.

Results of these articles will be presented under three main headings: (i) Development of this technology and the different commercially available manufacturing techniques, (ii) Clinical outcomes with digitally fabricated dentures and (iii) Clinician's preference and experience with digitally fabricated dentures.

\section{i) Development of this technology and manufac- turing techniques}

Computer-aided technology is a broad term that infers the use of computer skills to assist in the design, analysis, and manufacture of products. ${ }^{1}$ It involves either additive manufacturing (such as rapid prototyping) or subtractive manufacturing (such as computerized numerical control [CNC] machining).

In additive manufacturing, or 3-dimensional (3D) printing, images from a digital file are used to create a product by laying down successive layers of a selected material. While in subtractive manufacturing, images from a digital file are used to create a product by machining (cutting/milling) to physically remove material and achieve the desired geometry. The subtractive procedure is widely used and more popular in prosthodontics and represents a modern method for designing, developing, and 
manufacturing a dental restoration, completely or partially. ${ }^{39}$

Currently, there are 3 commercial entities available namely AvaDent digital dentures (Global Dental Science, Scottsdale, Ariz $)^{40}$, Dentca CAD-CAM dentures (Denta Inc, Los Angeles, Calif $)^{41}$, and Pala Digital Dentures (Heraeus Kulzer) ${ }^{42}$. Additionally companies like Dentsply, nSequence, and Ivoclar offer the possibility of applying digital technology in the fabrication of complete dentures. ${ }^{43}$

AvaDent offers a milling process of fabrication, and Dentca and Pala Dentures offer digital designing and then conventional processing of dentures. ${ }^{42}$ Dentca claims to be the world's first CAD/CAM denture manufacturer. ${ }^{41}$ Both Dentca and AvaDent have listed definitive clinical and laboratory protocols using exclusive dental materials, techniques, and laboratory support and both systems allow fabrication of complete dentures in only 2 clinical appointments ${ }^{40,41}$ unlike conventional denture protocols. The first clinical appointment is for systematic data gathering (impressions, occlusal vertical dimension, maxillomandibular relationships and tooth selection), and the second appointment is for denture insertion and adjustments. Both manufacturers have listed definitive clinical and laboratory protocols using exclusive dental materials, techniques, and laboratory support.

In 1994, Maeda et $a l,{ }^{13}$ a group of Japanese researchers published the first English scientific report on the concept of using computer- aided technology to fabricate complete dentures. ${ }^{14,16,17,21}$ They described the construction of complete dentures from photopolymerized composite resin material using rapid prototyping technology. In 1997, another Japanese group, Kawahata et al, ${ }^{14}$ investigated the concept of duplicating existing dentures digitally and milling them using a CNC milling machine. In 2012, Goodacre et $\mathrm{al}^{20}$ described the development of this technology using a basic CAD/CAM "proof-of-concept" denture base milled from Lucite with a 3-axis milling machine. Denture bases were subsequently milled from PMMA, and these dentures with milled denture bases were tried clinically in patients. ${ }^{20}$ Other researches have contributed to enhancements in this era, ranging from arranging teeth digitally ${ }^{15,18}$ to incorporating cone beam computed tomography $(\mathrm{CBCT})^{17}$ to scanning and manufacturing complete dentures either through rapid prototyping technology ${ }^{16,21}$ or CNC milling. ${ }^{15-18,20,21}$ Table 1 summarizes the studies that described techniques for digital arrangement of denture teeth and different techniques for the fabrication of digital complete dentures.

\section{ii) Clinical outcomes with digitally fabricated den- tures}

Digitally fabricated dentures has become a rapidly evolving technology yet little information is available on their clinical or patient-centred outcomes..$^{22,43-45}$ To the best of the authors knowledge, no studies that evaluated clinical outcomes with digitally designed and/or fabricated complete dentures were available until 2015. Before that, most articles were descriptions of techniques involved in fabrication, ${ }^{13-18,21}$ clinical reports, ${ }^{11,12,20,22,24}$ and a systematic review of the literature ${ }^{2}$ that focused solely on historical background and the associated developing technology. In 2016, another review was published by Bilgin et al but they also focused on CAD-CAM techniques for removable partial and complete denture fabrication providing historical information on the development and timelines of different techniques. ${ }^{34}$

The first clinical study that assessed clinical outcomes with digitally-fabricated dentures was conducted by Kattadiyil et al in 2015. ${ }^{25}$ They compared clinical treatment outcomes, patient satisfaction, and dental student preferences for digitally and conventionally fabricated complete removable dental prostheses in a predoctoral setting. This was followed by 3 other clinical trials in 2016. ${ }^{26,32,37}$ Table 2 summarizes the 4 clinical 
studies. All four clinical studies used the subtractive manufacturing (milling) technology in their research. Based on these studies, complete dentures fabricated by CAD/CAM technology appeared to be more amenable to clinical practice than dentures fabricated with rapid prototyping technology.

Recently in 2017, Al Helal and his colleagues were the first to conduct a clinical study that "objectively" assessed retention of digitally milled maxillary denture bases and compared it to that of conventional heat-polymerized denture bases. ${ }^{38}$ Their study included 20 participants with completely edentulous maxillary arches. Definitive polyvinyl siloxane impressions were scanned (iSeries; Dental Wings), and the standard tessellation language files were sent to Global Dental Science for the fabrication of a computer-aided design and computer-aided manufacturing (CAD-CAM) milled denture base (AvaDent). The impression was then poured to obtain a definitive cast that was used to fabricate a heat-polymerized acrylic resin denture base.

\section{Retention, stability, extension and adaptation of digitally fabricated dentures}

All four clinical studies displayed in Table 2 assessed the retention of digitally fabricated dentures. Kattadiyil et al reported significantly increased retention for the milled maxillary complete dentures compared to the conventional dentures fabricated for the same participant, even when the posterior palatal seal was not engraved in the milled dentures..$^{25}$ Saponaro et al reported that adequate denture retention was observed in 40 out of their 48 participants $(83 \%) .{ }^{26}$ Similarly, retention was rated as good in the study conducted by Bidra et al both at baseline and after a 1-year followup period. ${ }^{32}$ Schwindling and Stober compared the retention of milled versus injection-molded dentures. They found insignificant differences with mandibular bases however retention of maxillary milled bases was slightly superior to their injectionmolded equivalents. ${ }^{37}$
All previously mentioned studies assessed retention subjectively. The only published study that assessed retention objectively was conducted by $\mathrm{Al} \mathrm{Helal} \mathrm{et} \mathrm{al} \mathrm{using} \mathrm{a} \mathrm{custom-designed} \mathrm{testing}$ device. Each denture base (conventional and milled) was subjected to a vertical pulling force by using an advanced digital force gauge 3 times at 10-minute intervals. From the results obtained, the authors concluded that the retention offered by milled complete denture bases from prepolymerized poly(methyl methacrylate) resin was significantly higher than that offered by conventional heat polymerized denture bases. ${ }^{38}$

Two reported clinical studies assessed the stability and the extension of their digitally fabricated dentures. Kattadiyil et al reported both significantly higher stability and significantly better extension with digital dentures. ${ }^{25}$ Both parameters were rated as good at baseline in the study conducted by Bidra et al. After 1 year follow-up, stability remained good while extension was rated as excellent. ${ }^{32}$

Three studies assessed the adaptation and fit of digitally fabricated dentures. Kattadiyil et al reported significantly better adaptation with digital dentures compared to their conventional equivalents. ${ }^{25}$ In another study, adaptation of digital dentures was rated as excellent immediately after denture insertion however its rating decreased significantly to being fair after the 1 year follow up period. ${ }^{32}$ In contrast to retention, there was no significant difference in the adaptation of maxillary milled versus maxillary injection-molded dentures, however it was found to be superior for milled mandibular dentures. ${ }^{37}$

\section{Speech (phonetics), aesthetics and chewing effi- ciency with digitally fabricated dentures}

Speech (phonetics) and aesthetics were assessed by all four clinical studies. For both parameters, there were no significant differences between digital and conventional dentures in the study conducted by Kattadiyil et a ${ }^{25}$ and similarly Schwindling and Stober $^{37}$ found no significant differences between 
digitally milled and injection-molded dentures. Saponaro et $\mathrm{al}^{26}$ reported that out of their 48 participants, 1 experienced altered phonetics and 3 had dentures with poor aesthetic outcome.

Kattadiyil et $\mathrm{a}^{25}$ reported that patients experienced significantly improved chewing efficiency with digital dentures compared to their conventional ones. All three parameters (speech, aesthetics and chewing efficiency) were rated as excellent at baseline and even after one year in the study conducted by Bidra et al. ${ }^{32}$

\section{Centric relation, vertical dimension and occlu- sion in digitally fabricated dentures}

Kattadiyil et a ${ }^{25}$ reported insignificant differences between digital and conventional dentures for all three parameters. However, 1 participant had an anterior open occlusal relationship and 1 had an increased vertical dimension of occlusion with the digital dentures. Out of the 48 participants that were recruited in the study conducted by Saponaro et al 26, 3 had incorrect centric relations with their final dentures and 4 had improper vertical dimension. Based on the results reached by Schwindling and Stober $^{37}$, occlusion was slightly superior with milled over injection molded bases. On the contrary, vertical dimension was slightly superior with injection molded over milled denture bases.

\section{Efficiency of technique (number of clinical ap- pointments/visits)}

Kattadiyil et $\mathrm{al}^{25}$ reported that the mean number of insertion appointments (2) with the 2-visit protocol significantly reduced clinic time as it was found to be 205 minutes less for digital dentures. Similar findings were reported in Saponaro et $\mathrm{al}^{26}$ with a mean number of insertion appointments of 2.39 with the 2-visit protocol indicating the need for less clinic time. However this benefit was offset by the increased communication time with laboratory. In the study conducted by Schwindling and Stober ${ }^{37}$, the treatment protocol itself was based on 4 clinical appointments. However, corrections that involved esthetic problems (such as excessive lip support, shifted midlines, deviations from the interpupillary line or Camper plane) were reassessed in an additional session. This extra session increased the total number of clinical sessions to an average of 5.4 instead of 4 .

\section{Patient satisfaction and preference}

Kattadiyil et $\mathrm{al}^{25}$ reported that their participants were more comfortable with their maxillary digital dentures. In fact 12 out of the 15 participants were found to be more satisfied and preferred their digital dentures over their conventional ones. Comparable results were reported in the study conducted by Bidra et $\mathrm{al}^{32}$, were $79 \%$ of the participants were satisfied with their digital dentures.

\section{iii) Clinician's preference and experience with dig- itally fabricated dentures}

In the study by Kattadiyil et al, ${ }^{25}$ predoctoral students fabricated both the digital and conventional dentures for the participants under faculty supervision. Faculty rated both denture types as regards different aspects and the students were requested to provide feedback by responding to the following 4 item questionnaire: (1) which denture technique (conventional or digital) was technically easier to perform? (2) Which denture technique would you like to use in your practice? (3) Which denture technique would you be more confident in performing without faculty supervision? And (4) Do you have any additional comments? Results revealed significantly higher Faculty ratings in favour of the digital dentures as regards retention, stability, denture base contour, fit, extension, and overall result. However, no significant differences were found in other aspects such as aesthetics, lip support, phonetics, quality of tooth arrangement, occlusion, appropriate OVD, accuracy of centric relation, and prognosis. As for student responses, results revealed significant preference of the digital dentures for questions 1 and 2 indicating that they thought digital dentures were easier to 
perform and they would prefer its use in their dental practice; However, they did not express a significant difference in confidence in carrying out the fabrication procedures for either dentures without any faculty supervision, implying that they felt both techniques involved a learning curve. 7 students recorded "no required laboratory work" as an advantage. 6 students pointed out "improved festooning and denture base finish" compared to their previous conventional work that they had been accustomed to.

Schwindling and Stober $^{37}$ reported that the procedures used to fabricate the 2 types of digital dentures (milled and injection-molded) were clinically feasible. However, a few complications, mainly aesthetic issues, occurred during the fabrication process. They suggested that this may be due to lack of clinical experience (such as with the recording instruments or with adjustment of ideal lip support) or laboratory experience (such as custom tray border lengths or deviations from the interpupillary and Camper planes) with the new devices. They concluded that an additional session could increase the predictability of aesthetic outcomes for less experienced users of the system.

TABLE (1) Studies that described techniques for digital arrangement of denture teeth and fabrication of digital complete dentures

\begin{tabular}{|c|c|c|}
\hline \multicolumn{3}{|c|}{ Articles describing digital arrangement of denture teeth } \\
\hline $\begin{array}{l}\text { Busch and Kordass } \\
\text { (2006) }\end{array}$ & \multicolumn{2}{|c|}{$\begin{array}{l}\text { Models of edentulous arches were 3D scanned. Software detects and automatically reconstructs the } \\
\text { reference structures that are anatomically important for the set-up of artificial teeth. Occlusal plane is semi- } \\
\text { automatically defined and front dental arch is designed. After these design features have been determined, } \\
\text { artificial teeth are selected from a database and set up automatically. The dental technician can assess the } \\
\text { esthetics and function of the suggested dental set-up on the computer screen and make slight corrections } \\
\text { if necessary. }\end{array}$} \\
\hline Zhang et al (2011) & \multicolumn{2}{|c|}{$\begin{array}{l}\text { Tooth arrangement performed by using prototype multi-manipulator tooth arrangement robot system. } \\
\text { Multi-manipulator tooth-arrangement robot system consisted of } 14 \text { independent manipulators ( } 1 \text { for each } \\
\text { denture tooth), dental arch generator, and slipway mechanism. }\end{array}$} \\
\hline \multicolumn{3}{|c|}{ Articles describing fabrication of digital dentures using Rapid prototyping technology } \\
\hline Article & Data acquisition & Denture fabrication \\
\hline Maeda et al (1994) & $\begin{array}{l}\text { 3D laser scanner and charge coupled-device }(\mathrm{CCD}) \text { cameras } \\
\text { of double-arch impressions made with silicone impression } \\
\text { material and a specialized custom tray. }\end{array}$ & $\begin{array}{l}\text { Rapid Prototyping (3D laser lithography) } \\
\text { technology as } 2 \text { outer shells (cameo/ } \\
\text { occlusal surface and intaglio/tissue } \\
\text { surface), which was then connected by } \\
\text { using predetermined reference points. }\end{array}$ \\
\hline Sun et al (2008) & $\begin{array}{l}\text { 3D laser scanning of edentulous casts and occlusal rims, } \\
\text { followed by digital tooth arrangement and creation of virtual } \\
\text { flasks for denture processing. }\end{array}$ & $\begin{array}{l}\text { Rapid Prototyping technology to create } \\
\text { physical flasks, followed by insertion } \\
\text { of teeth and conventional laboratory } \\
\text { procedures to fabricate complete dentures }\end{array}$ \\
\hline $\begin{array}{l}\text { Inokoshi et al11 } \\
(2012)\end{array}$ & $\begin{array}{l}\text { CBCT scans of wax trial dentures of } 10 \text { patients, followed by } \\
\text { various modifications performed on computer. }\end{array}$ & $\begin{array}{l}\text { Rapid Prototyping technology to create } 7 \\
\text { prototype dentures for each patient with } \\
\text { various alterations in tooth positions } \\
\text { to study feasibility of using prototype } \\
\text { dentures for trial placement purposes. }\end{array}$ \\
\hline
\end{tabular}




\begin{tabular}{|c|c|c|}
\hline \multicolumn{3}{|c|}{ Articles describing fabrication of digital dentures using Computerized numerical control (CNC) milling } \\
\hline Article & Data acquisition & Denture fabrication \\
\hline $\begin{array}{l}\text { Kawahata et al } \\
\text { (1997) }\end{array}$ & $\begin{array}{l}\text { CCD cameras assisted by lasers to record digital images of } \\
\text { cameo and intaglio surfaces of set of complete dentures of } \\
\text { patient. }\end{array}$ & $\begin{array}{l}\text { CNC milling by using block of wax to } \\
\text { create duplicate denture. }\end{array}$ \\
\hline $\begin{array}{l}\text { Kanazawa et al } \\
(2011)\end{array}$ & $\begin{array}{l}\text { Separate extraoral cone beam computed tomography (CBCT) } \\
\text { scans of patient's dentures and artificial teeth, followed by } \\
\text { virtual tooth arrangement. }\end{array}$ & $\begin{array}{l}\text { CNC milling of denture base by using a } \\
\text { clear block of acrylic resin, followed by } \\
\text { manual bonding of denture teeth into the } \\
\text { recesses of base. }\end{array}$ \\
\hline $\begin{array}{l}\text { Goodacre et al } \\
(2012)\end{array}$ & $\begin{array}{l}\text { Scan of silicone impressions made by neutral zone technique } \\
\text { and scan of interocclusal records, followed by virtual tooth } \\
\text { arrangement. }\end{array}$ & $\begin{array}{l}\text { CNC milling of denture base by using pink } \\
\text { block of acrylic resin, followed by manual } \\
\text { bonding of denture teeth into recesses of base. }\end{array}$ \\
\hline Infante et al (2014) & $\begin{array}{l}\text { PVS Impressions are made; maxilla-mandibularrelation } \\
\text { records are made using a special anatomic measuring device } \\
(\mathrm{AMD}) \text {. Anterior tooth position and selection of an appropriate } \\
\text { tooth mold is done with a specific esthetic transparent guide. } \\
\text { The completed impressions and the final AMD are sent to the } \\
\text { lab. A virtual denture is generated. }\end{array}$ & $\begin{array}{l}\text { The virtual denture is then milled to } \\
\text { exact specifications with a 5-axis milling } \\
\text { machine. }\end{array}$ \\
\hline $\begin{array}{l}\text { McLaughlin \& Van } \\
\text { Ramos (2015) }\end{array}$ & $\begin{array}{l}\text { PVS definitive impressions are made. Posterior palatal seal } \\
\text { area is marked on the maxillary impression. Impressions are } \\
\text { then sent to the lab for scanning and designing the denture } \\
\text { bases. }\end{array}$ & $\begin{array}{l}\text { Only the denture bases are fabricated } \\
\text { using CNC milling. All subsequent steps } \\
\text { of denture fabrication are carried out } \\
\text { conventionally using the milled bases. }\end{array}$ \\
\hline $\begin{array}{l}\text { Wimmer et al } \\
(2016)\end{array}$ & $\begin{array}{l}\text { Definitive impressions are made; Jaw relationship records } \\
\text { are made and sent to the lab for mounting. Definitive casts } \\
\text { are scanned separately with an optical scanner then the casts } \\
\text { and the occlusion rims are scanned. Data is imported into the } \\
\text { software to create a virtual design of the complete dentures. }\end{array}$ & $\begin{array}{l}\text { Denture bases are milled with a 5-axis } \\
\text { milling machine from a gingiva-colored } \\
\text { wax blank. Denture teeth are waxed into } \\
\text { the sockets of the wax bases. Completed } \\
\text { trial dentures are evaluated then sent to the } \\
\text { dental laboratory for processing. }\end{array}$ \\
\hline Yilmaz et al (2016) & $\begin{array}{l}\text { Definitive impressions are made using zinc oxide eugenol. } \\
\text { Posterior palatal seal areas are marked and transfered to } \\
\text { maxillary impression. Maxillomandibular relationship } \\
\text { (MMR) records were made. Impressions and MMR records } \\
\text { are sent to the Lab for scanning and digitizing. Scanned } \\
\text { images are aligned to each other by matching } 3 \text { corresponding } \\
\text { points in the software. Scanned casts are mounted virtually } \\
\text { followed by denture base design and virtual tooth arrangement } \\
\text { using the software. }\end{array}$ & $\begin{array}{l}\text { The milling process starts with the core } \\
\text { element (milling blank with different tooth } \\
\text { sizes). This blank in the dental arches is } \\
\text { integrated in a functional and esthetic } \\
\text { arrangement. Milling can be processed } \\
\text { using the } 3+2 \text { axis, as well as the } 5 \text {-axis } \\
\text { simultaneous milling technique. }\end{array}$ \\
\hline $\begin{array}{l}\text { Schweiger et al } \\
(2017)\end{array}$ & $\begin{array}{l}\text { Definitive impressions are made and used as record bases } \\
\text { for the occlusal registration record which is adjusted to the } \\
\text { proper VDO to create the impression occlusal record (IOR). } \\
\text { Patient's face is scanned in } 3 \text { different positions one with IOR } \\
\text { in place. The } 3 \text { face scans are aligned virtually by using best- } \\
\text { fit alignment software. IOR is scanned with a lab scanner. } \\
\text { Stone casts are poured and digitized. Stereolithography } \\
\text { (STL) data of the IOR are aligned with the face scan using a } \\
\text { best-fit algorithm and reference markings on the IOR. STL } \\
\text { records of the scanned impressions and the IOR are sent to } \\
\text { the fabrication center where the virtual tooth arrangement is } \\
\text { conducted. }\end{array}$ & $\begin{array}{l}\text { Virtual tooth arrangement data are } \\
\text { imported them into the face scanner } \\
\text { software. Vrtual evaluation of the digital } \\
\text { tooth arrangement is carried out. After } \\
\text { any necessary modifictions, the denture is } \\
\text { fabricated through CNC milling. }\end{array}$ \\
\hline
\end{tabular}


Table (2) Clinical studies that assessed clinical outcomes with digitally-fabricated dentures

\begin{tabular}{|c|c|c|c|c|}
\hline & $\begin{array}{l}\text { Kattadiyil } \\
\text { et al (2015) }\end{array}$ & $\begin{array}{l}\text { Saponaro } \\
\text { et al }(\mathbf{2 0 1 6})\end{array}$ & $\begin{array}{l}\text { Bidra et al } \\
(2016)\end{array}$ & $\begin{array}{l}\text { Schwindling and } \\
\text { Stober (2016) }\end{array}$ \\
\hline Study design & $\begin{array}{l}\text { A comparative clinical } \\
\text { prospective study }\end{array}$ & $\begin{array}{l}\text { A non-comparative } \\
\text { clinical retrospective } \\
\text { cross-sectional study }\end{array}$ & $\begin{array}{l}\text { A non-comparative } \\
\text { clinical prospective } \\
\text { pilot cohort study }\end{array}$ & $\begin{array}{l}\text { A comparative } \\
\text { clinical } \\
\text { prospective pilot } \\
\text { study }\end{array}$ \\
\hline $\begin{array}{l}\text { Number (average } \\
\text { age) of participants }\end{array}$ & $\begin{array}{l}15 \text { patients (average } \\
\text { age } 55 \text { years) }\end{array}$ & $\begin{array}{l}48 \text { patients (average age } \\
\text { of } 62.79 \text { years) }\end{array}$ & $\begin{array}{l}14 \text { patients (average age of } \\
68.4 \text { years) }\end{array}$ & $\begin{array}{l}5 \text { patients (average } \\
\text { age not specified) }\end{array}$ \\
\hline $\begin{array}{l}\text { P a r t i c i p a n t s } \\
\text { classification used }\end{array}$ & $\begin{array}{l}\text { Prosthodontic index } \\
\text { classification (All had } \\
\text { Class I or II ) }\end{array}$ & - & - & House classification \\
\hline $\begin{array}{l}\text { Methodology and } \\
\text { study setting }\end{array}$ & $\begin{array}{l}\text { Each patient received } \\
1 \text { set of conventional } \\
\text { ( } 5 \text { - a p point me } \mathrm{n} \text { ) } \\
\text { prosthesis and } 1 \text { set of } \\
\text { digital (2-appointment) } \\
\text { (AvaDent) prosthesis } \\
\text { fabricated by senior } \\
\text { predoctoral students } \\
\text { under faculty } \\
\text { supervision in a pre- } \\
\text { doctoral clinic. }\end{array}$ & $\begin{array}{l}\text { Patients who had re- } \\
\text { ceived CAD-CAM- } \\
\text { fabricated CDs between } \\
2012 \text { and } 2014 \text { were } \\
\text { identified from a retro- } \\
\text { spective chart review. } \\
\text { Two visits protocol us- } \\
\text { ing bonded commercial } \\
\text { teeth to milled CD/CD } \\
\text { base (Global Dental Sci- } \\
\text { ence). Clinical steps per- } \\
\text { formed by predoctoral } \\
\text { and postgraduate dental } \\
\text { students in pre- and post- } \\
\text { graduate clinics. }\end{array}$ & $\begin{array}{l}\text { Participants with existing } \\
\text { maxillary CDs opposing } \\
\text { either mandibular CDs or } \\
\text { IODs that required replace- } \\
\text { ment were recruited. A } \\
\text { 2-visit duplicate denture } \\
\text { protocol was used to fab- } \\
\text { ricate monolithic milled } \\
\text { dentures (Global Dental } \\
\text { Science). Clinical steps } \\
\text { performed by } 2 \text { experi- } \\
\text { enced prosthodontists (at } \\
\text { least } 5 \text { years of clinical ex- } \\
\text { perience) in a post-graduate } \\
\text { clinic }\end{array}$ & $\begin{array}{l}\text { Digitally designed } \\
\text { CDs with two meth- } \\
\text { ods of fabrication, } \\
\text { milled and injec- } \\
\text { tion molding. Four } \\
\text { visit protocol using } \\
\text { bonded commercial } \\
\text { teeth to milled CD/ } \\
\mathrm{CD} \text { base, (Wieland } \\
\text { Dental) compared to } \\
\text { injection molding. } \\
\text { Steps performed by } 2 \\
\text { faculty members in a } \\
\text { prosthodontic faculty } \\
\text { clinic. }\end{array}$ \\
\hline $\begin{array}{l}\text { Occlusal scheme } \\
\text { used }\end{array}$ & \multicolumn{3}{|c|}{ Lingualized occlusal scheme (15-degree teeth) } & $\begin{array}{l}\text { Bilateral balanced } \\
\text { scheme. }\end{array}$ \\
\hline $\begin{array}{l}\text { Instrument for } \\
\text { assessment }\end{array}$ & $\begin{array}{l}\text { A 5-point Likert rating } \\
\text { scale from } 0 \text { (remake) } \\
\text { to } 4 \text { (excellent) was } \\
\text { used by faculty and } \\
\text { patients }\end{array}$ & - & $\begin{array}{l}\text { A } 100-\mathrm{mm} \text { visual analog } \\
\text { scale (VAS) was used. } \\
\text { Favorable } \\
(70.1-100) \text { and unfavorable } \\
(<70) \text {. Favorable ratings } \\
\text { were sub-divided as } \\
\text { excellent (90.1-100), good } \\
(80.1-90) \text {, and fair (70.1- } \\
80) \text {. }\end{array}$ & $\begin{array}{l}\text { A 6-point scale } \\
\text { ranging from poor } \\
\text { (grade } 6 \text { ) to excellent } \\
\text { (grade } 1 \text { ). }\end{array}$ \\
\hline $\begin{array}{l}\text { Time of data } \\
\text { collection }\end{array}$ & 1-week post insertion & Immediate post-insertion & $\begin{array}{l}\text { Immediate post-insertion } \\
\text { (baseline) and } 1 \text { year later }\end{array}$ & $\begin{array}{l}\text { Immediate } \\
\text { insertion }\end{array}$ \\
\hline
\end{tabular}




\section{DISCUSSION}

\section{Advantages, disadvantages and limitations of digitally fabricated dentures}

The conventional method of fabricating complete dentures has proved to be clinically predictable for almost a century. ${ }^{1}$ A key advantage for this method is the ability to modify or customize tooth arrangements and to confirm all preceding steps prior to the try -in stage. However, there are some disadvantages inherent in the conventional method including: 1) the need for at least 4 to 5 clinical appointments with additional post insertion visits; 2) high treatment costs due to increased patient visits; 3) variable laboratory timings and expenses;

4) lack of intimate adaptation of denture bases to the underlying tissues due to polymerization shrinkage; and 5) difficulty in creating an optimal duplicate denture. ${ }^{46}$

Implementation of CAD/CAM technology in complete denture prosthodontics may ameliorate these disadvantages. Several anticipated advantages of digitally constructed dentures have been reported. The main advantage is the reduced number of clinical visits, as few as 2 appointments, which is beneficial for both clinicians and patients especially the elderly. ${ }^{2}$ This in turn results in reduced cost for the patient and the clinician. Other potential advantages include : 1) superior strength and better fit as the denture base is milled from a prepolymerized block of acrylic resin; 2) minimal porosity leading to reduced potential for dentures to harbor microorganisms such as Candida albicans and consequently reduced infections; 3) stored digital data makes creation of duplicate dentures (reproducibility) easier; 4) increased ability for better quality control as well as 5) improved potential for standardization in clinical research on complete dentures as well as implant-retained overdentures. ${ }^{2}$ A further implicit advantage is the fact that complete denture treatment is a reversible and a non-invasive form of intervention. If the
CAD/CAM denture failed to satisfy the patient or clinician's requirements, the clinician is capable of reverting to the conventional denture fabrication method, or removing the artificial teeth from the CAD/CAM denture. The milled denture base can then be used to proceed with subsequent steps of maxillomandibular relationship, trial placement, and denture processing using conventional methods. ${ }^{2}$

Despite all these advantages, there are still some limitations and disadvantages of the current commercial systems. It is very challenging to optimally evaluate vertical dimension of occlusion, maxillomandibular relationship, lip support, and maxillary incisal edge position with these systems. Establishing the mandibular occlusal plane is impossible. These disadvantages may require remaking the denture at an additional cost and time. A significant disadvantage is that clinicians and patients lack the opportunity to evaluate a trial denture intraorally and that the patient's input is minimal with such systems. Although one of the manufacturers (Avadent) ${ }^{40}$ has partially addressed this disadvantage however additional treatment expenses are involved. ${ }^{2}$ McLaughlin and Van Ramos ${ }^{33}$ tried to alleviate this disadvantage in their research by constructing digital (CAD/ CAM) denture bases and using these bases for the subsequent denture fabrication steps. Hence, the conventional trial stage is performed allowing the correction of any OVD discrepancies or any issues with phonetics, aesthetic or tooth arrangements, unlike the traditional method of CAD/CAM denture fabrication. This approach took advantage of the benefits of this new technology while avoiding some of its drawbacks by maintaining control of the important details of the prosthesis. This technique also eliminated polymerization shrinkage in the record base, minimized polymerization shrinkage while processing teeth to the base, and reduced occlusal errors, hence providing a complete denture with an intimate fit to the underlying mucosa and minimal occlusal errors. 
Certain manual steps are still essential and cannot be eliminated even when considering computeraided denture fabrication in denture construction. Impressions of edentulous arches are still made using conventional techniques and materials. A complete digital impression of edentulous arches is very challenging and not as easy as for tooth preparations/implant abutments because they require registration with a dynamic movement of the muscles and jaws. This may be difficult to execute with an intraoral 3D scanner. This is a gap that still needs to be addressed by future research. Another manual step in some of the techniques described is the bonding of artificial teeth into the recesses of the denture base in the lab. Further research should focus on understanding and investigate the strength of this bond or even eliminating this procedure by milling the denture in 1 piece with the artificial teeth. ${ }^{2}$

Another potential limitation is that the current material cost and laboratory expenses are relatively higher than the conventional methods. However it is believed that with the advancement and broader acceptance of this technology, the expenses of materials and laboratory support can decrease to be significantly lower than conventional methods. ${ }^{2}$

\section{Clinical performance of digitally fabricated complete dentures}

Generally and from a subjective perspective, digitally fabricated dentures were found to provide favourable retention compared to conventional dentures especially for maxillary arches ${ }^{25,37}$ and for milled versus injection molded digital dentures. ${ }^{37}$ It also seemed that this favourable retention could be maintained by the same degree after one year of service. ${ }^{32}$ These subjective findings were supported by an objective assessment conducted by Al Helal et al who proved that retention of maxillary digital dentures was found to be "quantitatively "superior to their conventional equivalents. ${ }^{38}$ This superior retention has been attributed to the fact that milling digital dentures from a prepolymerized block of acrylic resin eliminates polymerization shrinkage that is inevitable in the conventional methods. ${ }^{25}$ Consequently, a more intimate fit and adaptation between the denture base and the underlying tissues could be achieved. This assumption is supported by the subjectively high ratings recorded for the digital dentures as regards adaptation and fit criteria in the study conducted by Kattadiyil et al. ${ }^{25}$ It is noteworthy however that in one of the studies, 8 out of 48 patients experienced lack of denture retention on the day of denture insertion. ${ }^{26}$ The authors explained that this could be attributed to one of two reasons. The first was the absence of a posterior palatal seal. They suggested that although a posterior palatal seal is not required because there is no polymerization shrinkage of the acrylic resin; it could still be requested in the prescription order. The second reason was that some of the definitive impressions that were sent to the company for scanning and consequent milling of the denture bases may have been inaccurate or improperly made.

Patients also experienced significantly improved stability and chewing efficiency with digital dentures compared to their conventional ones. ${ }^{25}$ Stability and chewing efficiency were in fact rated as good and excellent respectively, both immediately after denture insertion and maintained this rating even after the patients used their digital dentures for one year. ${ }^{32}$ The improved retentive qualities inherent in digital dentures may have positively and favourably influenced these two parameters. A retentive denture is usually stable during function which in return allows the patient to chew effectively as the muscular power would be dedicated fully to crushing and chewing the food rather than partly chewing and partly trying to seat the denture in place.

One study revealed that aesthetics and appearance with digitally constructed dentures seemed to be insignificantly different to conventional dentures. ${ }^{25}$ 
However, some aesthetic issues (such as excessive lip support, shifted midlines, deviations from the interpupillary line or Camper plane, and excessive gingival display) were correlated with digital dentures. ${ }^{26}$ These concerns could be related to the lack of the conventional aesthetic trial appointment in which the dentures could be more personalized and individualized to satisfy the aesthetic needs of each patient. Difficulty in assessing the digital preview images as some students remarked in the study conducted by Kattadiyil et al may have also contributed to these aesthetic concerns. ${ }^{25}$ Schwindling and Stober reported that they needed to re-assess and correct these aesthetic issues in an additional session which consequently increased the number of clinical visits. ${ }^{37}$

\section{Clinical appointments and post-insertion visits with digitally fabricated dentures}

One of the main advantages cited for digital dentures has been the reduction of the number of appointments from 5 visits (conventional method) to 2 visits as the commercially available systems claim. Saponaro et al reported a mean of 2.39 clinical visits and added that even if some patients required a third visit, this was still considered a significant reduction in the number of 5 appointments conventionally required. ${ }^{26}$

Kattadiyil et a ${ }^{25}$ reported that the 2-visit protocol that they adopted reduced the total clinical time significantly with an average of 205 minutes less for the digital dentures compared to the conventional dentures. Bidra et $\mathrm{al}^{32}$ also reported reduction in clinical time for digital denture fabrication. However the authors mentioned that this advantage was offset by the considerable time that was devoted to the communication with the laboratory so as to ensure acceptable and good-quality outcomes. An average of 5 emails per participant (0-11) was sent to the lab to discuss the CAD design of the dentures.

The 2-visit CAD/CAM fabrication of complete dentures was hence found to be a viable treatment option for both clinicians and patients, however careful patient selection must be considered. Application of a 2-visit protocol with this technology also requires considerable experience in the clinical and laboratory aspects of digital designing. For more satisfactory results, additional time and effort may be required to assess digital previews and participate in the electronic communication process with the laboratory technician. ${ }^{32}$ So even though the clinical chairside time may be reduced, considerable nonchairside time is usually required by dentists for the planning, communication, and execution of digital dentistry procedures. Developments in protocols, promoting clinicians' education and experience with this new technology may speed up this practice in the future.

It is worthy to mention however that not all systems are intended for a 2-appointment process. Schwindling and Stober described a 4-visit CADCAM system that included a trial placement visit. Nonetheless, they concluded that additional clinical visits should be expected with less experienced clinicians to correct some issues that are mainly related to aesthetic factors. Based on their results, a mean of 5.4 clinical visits was required to complete the fabrication process. ${ }^{37}$

The number of post-insertion visits required with digital dentures was found to be reasonable. Saponaro et al reported that 6 participants did not require any postinsertion adjustment visits, 16 participants required only 1 postinsertion visit, 14 participants required 2 visits, and 12 required 3 or more visits. This resulted in a mean number of 2.08 postplacement adjustment visits which seems practical and comparable to conventional protocols. ${ }^{26}$ Similarly, Bidra et al reported an average of 3.3 denture adjustments over a period of 1 year for their 14 participants and their results revealed statistically significant improvement in ratings for absence of denture sore spots after the 1-year evaluation. The 
superior retention and improved adaptation and fit offered by digital dentures may have significantly decreased the movement of the dentures during function which may have contributed to this relatively low rate of post-insertion visits. ${ }^{32}$

\section{CONCLUSIONS}

Within the limitations of this review, the following conclusions were drawn:

- Digitally fabricated dentures can be an effective and time-efficient option for completely edentulous patients as this new technology simplifies the treatment process and provides clinically acceptable prostheses with few complications.

- Digital dentures were found to be preferred by clinicians, predoctoral students and patients.

- Clinical and patient-centered outcomes with digital dentures were found to be favourable compared to conventional dentures.

- The main advantages reported with digitally fabricated dentures were the significantly reduced clinical time and number of appointments, improved retention, digital archivability and hence reproducibility.

- Although the 2-visit CAD/CAM fabrication of complete dentures could be considered a viable treatment option for both clinicians and patients, however careful patient selection must be considered. The application of the 2-visit protocol also requires considerable experience in the clinical and laboratory aspects of digital designing. For more satisfactory results, additional time and effort may be required to assess digital previews and participate in electronic communication with the lab.

- Dental literature lacks short-term and long term prospective clinical studies in this field to be able to reach definitive conclusions.

\section{RECOMMENDATIONS}

Dental literature lacks long term clinical trials that are necessary to validate this technology in complete denture prosthodontics. Since there is a persistent need to improve dental education with regard to complete dentures, prospective and standardized clinical studies on digitally fabricated dentures with substantial sample sizes and longer follow-up periods are required to validate the performance of this treatment alternative. This is essential to improve patient care and to provide evidence-based research that addresses treatment and patient-centred outcomes of this evolving technology.

\section{REFERENCES}

1. Jacob RF. The traditional therapeutic paradigm: complete denture therapy. J Prosthet Dent 1998;79:6-13.

2. Bidra AS, Taylor TD, Agar JR. Computer-aided technology for fabricating complete dentures: Historical background, current status and future perspectives. J Prosthet Dent 2013;109:361-6.

3. Reich S, Endres L, Weber C, Wiedhahn K, Neumann P, Schneider O, et al. Three-unit CAD/CAM-generated lithium disilicate FDPs after a mean observation time of 46 months. Clin Oral Investig 2014;18:2171-8.

4. Neves FD, Prado CJ, Prudente MS, Carneiro TA, Zancopé K, Davi LR, et al. Micro-computed tomography evaluation of marginal fit of lithium disilicate crowns fabricated by using chairside CAD/CAM systems or the heat-pressing technique. J Prosthet Dent 2014;112:1134-40.

5. de França DG, Morais MH, das Neves FD, Barbosa GA. Influence of $\mathrm{CAD} / \mathrm{CAM}$ on the fit accuracy of implantsupported zirconia and cobalt-chromium fixed dental prostheses. J Prosthet Dent 2015;113:22-8.

6. Miyazaki T, Hotta Y, Kunii J, Kuriyama S, Tamaki Y. A review of dental $\mathrm{CAD} / \mathrm{CAM}$ : current status and future perspectives from 20 years of experience. Dent Mater J 2009;28:44-56.

7. Hamza TA, Ezzat HA, El-Hossary MM, Katamish HA, Shokry TE, Rosenstiel SF. Accuracy of ceramic restorations made with two CAD/CAM systems. J Prosthet Dent 2013;109:83-7. 
8. Patzelt SB, Emmanouilidi A, Stampf S, Strub JR, Att W. Accuracy of full-arch scans using intraoral scanners. Clin Oral Invest 2014;18:1687-94.

9. Alghazzawi TF. Advancements in CAD/CAM technology: options for practical implementation. J Prosthodont Res 2016;60:72-84

10. Kattadiyil MT, Mursic Z, AlRumaih H, Goodacre CJ. Intraoral scanning of hard and soft tissues for partial removable dental prosthesis fabrication. J Prosthet Dent 2014;112:444-8.

11. Bidra AS. The 2-visit CAD-CAM implant-retained overdenture: a clinical report. J Oral Implantol 2014; 40:722-8.

12. Lozada JL, Garbacea A, Goodacre CJ, Kattadiyil MT. Use of a digitally planned and fabricated mandibular complete denture for easy conversion to an immediately loaded provisional fixed complete denture. Part 1. Planning and surgical phase. Int J Prosthodont 2014;27:417-21.

13. Maeda Y, Minoura M, Tsutsumi S, Okada M, Nokubi T. A CAD/CAM system for removable denture. Part I: Fabrication of compete dentures. Int $\mathrm{J}$ Prosthodont 1994;7:17-21.

14. Kawahata N, Ono H, Nishi Y, Hamano T, Nagaoka E. Trial of duplication procedure for complete dentures by CAD/ CAM. J Oral Rehabil 1997;24:540-8.

15. Busch M, Kordass B. Concept and development of a computerized positioning of prosthetic teeth for complete dentures. Int J Comput Dent 2006;9:113-20.

16. Sun Y, Lü P, Wang Y. Study on CAD\&RP for removable complete denture. Comput Methods Programs Biomed 2009;93:266-72.

17. Kanazawa M, Inokoshi M, Minakuchi S, Ohbayashi N. Trial of a CAD/CAM system for fabricating complete dentures. Dent Mater J 2011;30:93-6.

18. Zhang YD, Jiang JG, Liang T, Hu WP. Kinematics modeling and experimentation of the multi-manipulator tootharrangement robot for full denture manufacturing. J Med Syst 2011;35:1421-9.

19. Galhano GA, Pellizzer EP, Mazaro JV. Optical impression systems for CADCAM restorations. J Craniofac Surg 2012;23:575-9.

20. Goodacre CJ, Garbacea A, Naylor WP, Daher T, Marchack CB, Lowry J. CAD/CAM fabricated complete dentures: concepts and clinical methods of obtaining required morphological data. J Prosthet Dent 2012;107:34-46.
21. Inokoshi M, Kanazawa M, Minakuchi S. Evaluation of a complete denture trial method applying rapid prototyping. Dent Mater J 2012;31:40-6.

22. Kattadiyil MT, Goodacre CJ, Baba NZ. CAD/CAM complete dentures: a review of two commercial fabrication systems. J Calif Dent Assoc 2013;41: 407-16.

23. Patzelt SB, Vonau S, Stampf S, Att W. Assessing the feasibility and accuracy of digitizing edentulous jaws. J Am Dent Assoc 2013;144:914-20.

24. Infante L, Yilmaz B, McGlumphy, Finger I. Fabricating complete dentures with CAD/CAM technology. J Prosthet Dent 2014;111:351-5.

25. Kattadiyil MT, Jekki R, Goodacre CJ, Baba NZ. Comparison of treatment outcomes in digital and conventional complete removable dental prosthesis fabrications in a predoctoral setting. J Prosthet Dent 2015;114:818-25.

26. Saponaro PC, Yilmaz B, Heshmati RH, McGlumphy EA. Clinical performance of CAD/CAM-fabricated complete dentures: a cross-sectional study. J Prosthet Dent 2016;116:431-5.

27. Fernandez MA, Nimmo A, Behar-Horenstein LS. Digital denture fabrication in pre- and postdoctoral education: a survey of US dental schools. J Prosthodont 2016;25:83-90.

28. Saponaro PC, Yilmaz B, Johnston W, Heshmati RH, McGlumphy EA. Evaluation of patient experience and satisfaction with $\mathrm{CAD} / \mathrm{CAM}$-fabricated complete dentures: a retrospective survey study. J Prosthet Dent 2016;116: 524-8.

29. Wimmer T, Gallus K, Eichberger M, Stawarczyk B. Complete denture fabrication supported by CAD/CAM. J Prosthet Dent 2016;115:541-6.

30. Goodacre BJ, Goodacre CJ, Baba NZ, Kattadiyil MT. Comparison of denture base adaptation between CADCAM and conventional fabrication techniques. J Prosthet Dent 2016;116:249-56.

31. Schweiger J, Güth JF, Edelhoff D, Stumbaum J. Virtual evaluation for CADCAM- fabricated complete dentures. J Prosthet Dent 2017;117:28-33.

32. Bidra AS, Farrell K, Burnham D, Dhingra A, Taylor TD, Kuo C. Prospective cohort pilot study of 2-visit CAD/ CAM monolithic complete dentures and implant-retained overdentures: clinical and patient-centered outcomes. J Prosthet Dent 2016;115:578-86. 
33. McLaughlin JB, Ramos V Jr. Complete denture fabrication with CAD/CAM record bases. J Prosthet Dent. 2015; 114(4):493-7

34. Bilgin MS, Baytaroglu EN, Erdem A, Dilber E. A review of computer-aided design/computer-aided manufacture technique for removable denture fabrication. Eur J Dent 2016;10:286-91.

35. Neumeier TT, Neumeier H. Digital immediate dentures treatment: A clinical report of two patients. J Prosthet Dent. 2016; 116(3):314-9.

36. Yilmaz B, Azak AN, Alp G, Ekşi H. Use of CAD-CAM technology for the fabrication of complete dentures: An alternative technique. J Prosthet Dent.doi: 10.1016/ j.prosdent. 2016.10.016. [Epub ahead of print]

37. Schwindling FS, Stober T. A comparison of two digital techniques for the fabrication of complete removable dental prostheses: a pilot clinical study. J Prosthet Dent 2016;116(5):756-763.

38. AlHelal A, AlRumaih HS, Kattadiyil MT, Baba NZ, Goodacre CJ. Comparison of retention between maxillary milled and conventional denture bases: A clinical study. J Prosthet Dent. 2017; 117(2):233-238.
39. The glossary of prosthodontic terms. J Prosthet Dent 2005;94:20-1.

40. AvaDent Digital Dentures; Global Dental Science LLC. Available at: http://www. avadent.com

41. Dentca- CAD/CAM Denture; Dentca Inc. Available at: http://www.dentca.com

42. Kattadiyil MT, AlHelal A. An update on computerengineered complete dentures: A systematic review on clinical outcomes. J Prosthet Dent. 2017; 117(4):478-485.

43. Bilgin MS, Erdem A, Aglarci OS, Dilber E. Fabricating complete dentures with CAD/CAM and RP technologies. J Prosthodont 2015;24:576-9.

44. Wimmer T, Gallus K, Eichberger M, Stawarczyk B. Complete denture fabrication supported by CAD/CAM. J Prosthet Dent 2015;81:44-9.

45. AlHelal A, Jekki R, Richardson PM, Kattadiyil MT. Application of digital technology in the prosthodontic management of a myasthenia gravis patient. J Prosthet Dent 2016;115:531-6.

46. Christensen GJ. Removable prosthodontics: a forgotten part of dentistry. Alpha Omegan 2006;99:26-8. 